\title{
GAMBARAN BODY IMAGE PADA REMAJA USIA 16 - 18 TAHUN
}

\author{
Nia Agustiningsih \\ Sekolah Tinggi Ilmu Kesehatan Kepanjen \\ nia_agustiningsih@stikeskepanjen-pemkabmalang.ac.id
}

\begin{abstract}
Adolescence is a period where physical, emotional and cognitive development or thinking occurs. Adolescents will evaluate the changes or physical development based on their thinking. The purpose of this study is to describe the body image of adolescents aged 16-18 years. This research is a descriptive research. The population in this study were all adolescents aged 16-18 years in Kromengan Vocational School with a simple random sampling technique with a sample of 149 people. The results showed that respondents who had a very good body image amounted to 5 people (3.35\%), who had good body image there were 74 people (49.66\%), who had enough body image 68 people $(45.64 \%)$ and there are 2 people who have body image (1.35\%). Based on these results, the majority of adolescents are able to adapt to physical changes and have positive acceptance so that information and education are needed that can maintain positive perceptions of adolescents and improve adolescent perceptions that are still lacking in self-acceptance seen by body image
\end{abstract}

Keyword : Body image, adolescence

Abstrak : Masa remaja merupakan masa dimana terjadi perkembangan fisik, emosional dan kognitif atau pemikiran. Remaja akan melakukan penilaian terhadap perubahan atau perkembangan fisik berdasarkan pemikirannnya. Tujuan dari penelitian ini adalah untuk mengetahui gambaran body image pada remaja usia $16-18$ tahun. Penelitian ini merupakan penelitian deskriptif. Populasi dalam penelitian ini adalah seluruh remaja usia 16 - 18 tahun di SMK Kromengan dengan tehnik pengambilan sampel simple random sampling dengan besar sampel 149 orang. Kuesioner yang digunakan untuk mengetahui body image diadaptasi dari Multidimensional Body-Self Relations Questionnaire-Appearance Scales (MBSRQ-AS). Hasil penelitian menunjukkan bahwa responden yang memiliki body image yang sangat baik berjumlah 5 orang $(3,35 \%)$, yang memiliki body image baik ada 74 orang $(49,66 \%)$, yang memiliki body image cukup ada 68 orang $(45,64 \%)$ dan yang memiliki body image kurang ada 2 orang $(1,35 \%)$. Berdasarkan hasil tersebut bahwa sebagain besar remaja mampu beradaptasi terhadap perubahan fisik dan memiliki penerimaan yang positip sehingga perlu adanya informasi dan edukasi yang bisa mempertahankan persepsi positip remaja dan meningkatkan persepsi remaja yang masih kurang terhadap penerimaan diri yang dilihat drai body image.

Kata Kunci: Body image, Remaja

\section{PENDAHULUAN}

Masa remaja merupakan masa pertumbuhan fisik dan perkembangan psikologis yang diawali pada pada masa pubertas dan berakhir pada masa transisi ke dewasa. Transisi pada remaja disertai dengan pengalaman baru dalam sosial, kognitif, fisik, emosional dan psikologis (Murray et al, 2011). Hal ini meliputi pemikiran, sikap dan perilaku dalam menilai tentang ukuran, keindahan, sensasi, fungsi, kebugaran dan kesehatan. Beberapa hasil penelitian menjelaskan pada masa remaja merupakan puncak evaluasi terhadap tubuh (body image) sehingga body image merupakan isu utama yang muncul pada remaja (Murray et al, 2011; Senin et al, 2017). Body image merupakan persepsi diri dan sikap diri terhadap tubuh yang merupakan hasil evaluasi subyektif dari pemikiran, perasaan dan perilaku yang berkaitan dengan tubuh (Paans et al, 2018; Murray et al, 2011).
Pada masa remaja masalah body image merupakan hal yang penting untuk mendapat perhatian (Murray et al, 2011; Senin et al, 2017). Hal ini berkaitan dengan fokus perhatian pada masa remaja adalah penilaian terhadap tubuh dan penampilan fisiknya. Penerimaan body image pada remaja berkaitan dengan pengalaman remaja dalam interaksi sehari - hari dengan teman sebaya, penerimaan dan perhatian teman sebaya. Adanya evaluasi negatif dari teman sebaya berkaitan dengan body image akan menyebabkan remaja memiliki pemikiran yang negatif terhadap body image sehingga akan menyebabkan penurunan penerimaan body image.

Hasil penelitian Marco et al (2017) menjelaskan penurunan penerimaan body image pada remaja sebagian besar berkaitan dengan berat badan dan bentuk yaitu bahwa 
remaja perempuan lebih dari $70 \%$ menginginkan tubuhnya menjadi kurus dan lebih dari $50 \%$ remaja laki - laki menginginkan tubuhnya berotot. Penelitian lain menjelaskan bahwa $59,7 \%$ remaja memiliki penerimaan body image yang rendah (Duchesne et al, 2016).

Penerimaan terhadap body image yang rendah akan bisa menyebabkan gangguan dan perubahan perilaku seperti depresi, dorongan untuk kurus, gangguan makan, dysmorphia tubuh, harga diri rendah,

\section{BAHAN DAN METODE}

Penelitian ini merupakan penelitian deskriptif. Penelitian dilakukan pada tanggal 21 Februari 2019 di SMK Kromengan. Variabel dalam penelitian ini body image pada remaja. Populasi dalam penelitian ini adalah seluruh remaja usia 16 - 18 tahun di SMK Kromengan. Pengambilan sampel dilakukan tehnik simple random sampling dengan kriteria penelitian yang sudah ditentukan oleh peneliti yaitu krieria inklusi meliputi remaja (siswa) yang bersedia menjadi responden dan sedang tidak sakit, sedangkan kriteria ekslusi dalam penelitian ini adalah remaja (siswa) yang sedang tidak hadir dalam penelitian atau sedang melaksanakan kegiatan sekolah yang tidak bisa diganggu. Kuesioner yang dan perilaku yang mengorbankan kesehatan seperti diet dan penggunaan steroid (Jones and Smolak, 2011; Murray et al, 2013; Gillen, 2015; Eisenberg et al, 2017). Menurut Vossbeck et al (2014) bahwa evaluasi terhadap body image bisa dilakukan dengan melakukan assesment terhadap evaluasi penampilan, orientasi penampilan, kepuasan terhadap area tubuh dan berat badan. Tujuan dari penelitian ini adalah untuk mengetahui gambaran body image pada remaja usia 16 18 tahun.

digunakan untuk mengetahui body image diadaptasi dari Multidimensional Body-Self Relations Questionnaire-Appearance Scales (MBSRQ-AS). Jumlah pertanyaan dalam kuesioner ini terdiri dari 34 pertanyaan yang terdiri dari Appearance Evaluation (7 soal), Appearance Orientation (12 soal), Body Area Satisfaction (9 soal) dan Overweight Preoccupation (4 soal) dan Self-Classified Weight (2 soal). Data dianalisis secara deskriptif dan disajikan dalam bentuk tabel distribusi frekuensi dan narasi. Dalam penelitian ini memperhatikan etika penelitian yaitu Informed consent, Anonymity, Confidentiality, justice, beneficience, non maleficience.

\section{HASIL}

Hasil yang diperoleh dari penelitian ditampilkan dalam tabel distribusi frekuensi dan narasi sebagai berikut:

Tabel 1 Karakteristik Responden

\begin{tabular}{llcc}
\hline \multirow{2}{*}{ Variabel } & \multicolumn{1}{c}{ Kategori } & \multicolumn{2}{c}{ Jumlah } \\
\cline { 3 - 4 } & & $\begin{array}{c}\text { Frekuensi } \\
\text { (orang) }\end{array}$ & Prosentase (\%) \\
\hline Jenis Kelamin & Laki - Laki & 86 & $57,72 \%$ \\
& Perempuan & 63 & $42,28 \%$ \\
& Total & $\mathbf{1 4 9}$ & $\mathbf{1 0 0 \%}$ \\
\hline Usia & Usia 16 - 17 tahun & 81 & $54,36 \%$ \\
& Usia > 17 - 18 tahun & 68 & $\mathbf{4 5 , 6 4 \%}$ \\
& Total & $\mathbf{1 4 9}$ & $\mathbf{1 0 0 \%}$ \\
\hline Penghasilan orang tua & $<1$ Juta & 85 & $57,05 \%$ \\
& 1-2 Juta & 46 & $30,87 \%$ \\
& $>2-3$ Juta & 13 & $8,72 \%$ \\
& $>3$ Juta & 5 & $3,36 \%$ \\
& Total & $\mathbf{1 4 9}$ & $\mathbf{1 0 0 \%}$ \\
\hline Idola & Memiliki idola & 118 & $\mathbf{7 9 , 1 9 \%}$ \\
& Tidak memiliki idola & 31 & $20,81 \%$ \\
& Total & $\mathbf{1 4 9}$ & $\mathbf{1 0 0 \%}$ \\
\hline
\end{tabular}

Berdasarkan data di atas diketahui bahwa sebagian besar remaja berjenis kelamin laki - laki yaitu sebanyak 86 orang $(57,72 \%)$, usia $16-17$ tahun berjumlah 81 orang $(54,32 \%)$, memiliki orang tua dengan penghasilan < 1 juta yaitu 85 orang $(57,05 \%)$, dan sebagian remaja memiliki idola yaitu 118 orang $(79,19 \%)$. 
Tabel 2 Body image

\begin{tabular}{clcc}
\hline Variabel & \multicolumn{1}{c}{ Kategori } & \multicolumn{2}{c}{ Jumlah } \\
\cline { 3 - 4 } & & $\begin{array}{c}\text { Frekuensi } \\
\text { (orang) }\end{array}$ & Prosentase (\%) \\
\hline Body Image & Sangat Baik & 5 & $3,35 \%$ \\
& Baik & 74 & $49,66 \%$ \\
& Cukup & 68 & $45,64 \%$ \\
& Kurang & 2 & $1,35 \%$ \\
& Sangat Kurang & 0 & $0 \%$ \\
& Total & $\mathbf{1 4 9}$ & $\mathbf{1 0 0 \%}$ \\
\hline
\end{tabular}

Berdasarkan tabel 2 diketahui bahwa sebagian besar remaja memiliki body image dengan kategori baik yaitu berjumlah 74 orang $(49,66 \%)$.

\section{PEMBAHASAN}

Berdasarkan tabel 2 diketahui bahwa sebagian besar remaja yaitu berjumlah 74 orang $(49,66 \%)$ memiliki body image dengan kategori baik. Faktor - faktor yang mempengaruhi body image menurut Tatangelo et al (2015) adalah faktor individu dan faktor sosiokultural. Faktor individu meliputi IMT (Indek Massa tubuh), usia, jenis kelamin dan psikologis.

Usia responden pada penelitian ini adalah usia remaja. Berdasarkan tabel 1 diketahui bahwa responden sebagian besar berusia $16-17$ tahun yaitu berjumlah 81 orang $(54,32 \%)$ dan usia $>17-18$ tahun berjumlah 63 orang $(42,28 \%)$. Remaja merupakan masa transisi dimana pada usia tersebut remaja mengalami perubahan tubuh akibat dari pertumbuhan dan perkembangan pada masa pubertas. Adanya perubahan selama usia remaja akan mempengaruhi kepuasan terhadap body image (Murray et al, 2011; Lipowski et al, 2016). Pada usia remaja terjadi perubahan yang berkaitan dengan pertumbuhan dan perkembangan fisik dan kognitif. Potter et al (2013) menjelaskan bahwa pertumbuhan dan perkembangan fisik dan kognitif akan mempengaruhi body image. Perubahan perkembangan normal seperti pubertas akan mempengaruhi body image dibanding komponen konsep diri yang lain. Pada remaja usia yang perlu mendapatkan perhatian berkaiatan dengan body image adalah usia 16 - 19 tahun dengan usia puncak adalah usia 17 tahun (Rawana and Morgan, 2014).

Faktor individu yang lain yang mempengaruhi body image adalah jenis kelamin. Berdasarkan tabel 1 bahwa jumlah responden yang berjenis kelamin laki - laki ada 86 orang $(57,72 \%)$ dan berjenis kelamin perempuan ada 63 orang $(42,28 \%)$. Masalah yang berkaitan dengan body image dapat terjadi pada laki - laki dan perempuan (Ricciardelli and Yager, 2016). Penurunan body image satisfaction bisa terjadi pada laki
- laki maupun perempuan. Menurut Tatangelo et al (2015) bahwa laki - laki dan perempuan bisa mengalami penurunan kepuasan body image akibat perubahan pada masa pubertas.

Faktor individu selanjutnya yang bisa mempengaruhi body image adalah psikologis. Setiap individu memiliki karakteristik psikologis yang berbeda. Remaja yang memiliki persepsi yang baik terhadap tubuhnya akan mampu beradaptasi dan menerima keadaan fisik sebagai hasil perubahan pertumbuhan dan perkembangan remaja. Sedangkan remaja yang memiliki persepsi yang kurang baik dan adanya tuntutan bahwa penampilan fisik harus sempurna maka remaja tersebut akan memiliki kecenderungan untuk mengalami penurunan body image satisfaction (Yang et al, 2017). Hal ini sesuai dengan hasil pada tabel 2 bahwa jumlah responden yang memiliki body image yang sangat baik berjumlah 5 orang $(3,35 \%)$, yang memiliki body image baik ada 74 orang $(49,66 \%)$, yang memiliki body image cukup ada 68 orang $(45,64 \%)$ dan yang memiliki body image kurang ada 2 orang (1,35\%). Menurut Ricciardelli and Yager (2016) bahwa kondisi psikologis berkaitan dengan internalisasi tentang perbandingan sosial bahwa wanita identik dengan kurus / langsing sedangkan laki - laki identik dengan badan yang berotot. Sifat perfeksionis setiap individu merupakan salah faktor yang berkaitan dengan penerimaan atau kepuasan terhadap body image.

Faktor sosiokultural yang mempengaruhi body image adalah perbandingan sosial, kondisi sosial ekonomi, dukungan keluarga, kelompok sebaya (Talen and Mann, 2009; Tatangelo et al, 2015; Yang et al, 2017; Latiff et al, 2018). Perbandingan sosial adalah persepsi sosial bahwa tubuh yang ideal bagi perempuan adalah langsing dan tubuh yang ideal bagi laki - laki adalah berotot (Ricciardelli and Yager, 2016; Latiff et al, 2018). Persepsi ini biasanya mengacu kepada figur - figur yang dijadikan panutan 
seperti artis yang diidolakan remaja melalui media sosial, televisi, majalah (Koyuncu et al, 2010; Eisenberg et al, 2017). Berdasarkan tabel 1 diketahui bahwa sebanyak 118 orang $(79,19 \%)$ memiliki idola dan sebanyak 31 orang $(20,81 \%)$ tidak memiliki idola namun dari keseluruhan responden yang memiliki body image kurang ada 2 orang (1,35\%). Hal ini menunjukkan bahwa sebagian besar remaja menerima kondisi penampilan fisik mereka meskipun remaja memiliki idola.

Faktor sosiokultural selanjutnya adalah kondisi sosial ekonomi. Dalam penelitian ini kondisi sosial ekonomi responden dilihat dari penghasilan orang tua yaitu bahwa sejumlah 85 orang $(57,05 \%)$ memiliki penghasilan < 1 juta, 46 orang $(30,87 \%)$ memiliki penghasilan 1-2 Juta, 13 orang $(8,72 \%)$ memiliki penghasilan $>2-3$ juta dan 5 orang $(3,36 \%)$ memiliki

\section{DAFTAR PUSTAKA}

Duchesne, A., Dion, J., Lalande, D., Bégin, C., Émond, C., Lalande, G., \& Mcduff, P. (2016). Body dissatisfaction and psychological distress in adolescents: Is self-esteem a mediator? http://doi.org/10.1177/1359105316631 196

Eisenberg, M. E., Ward, E., Linde, J. A., Gollust, S. E., \& Neumark-sztainer, D. (2017). Exposure to teasing on popular television shows and associations with adolescent body satisfaction. Journal of Psychosomatic Research, 103(September), 15-21. http://doi.org/10.1016/j.jpsychores.201 7.09.014

Gillen, M. M. (2015). Associations between positive body image and indicators of men ' $s$ and women' s mental and physical health. Body Image, 13, 6774.

http://doi.org/10.1016/j.bodyim.2015.01 .002

Jones, D. C., \& Smolak, L. (2011). Body Image during Adolescence: A Developmental Perspective. Encyclopedia of Adolescence, Three-Volume Set (Vol. 1). Elsevier Inc. http://doi.org/10.1016/B978-0-12373951-3.00005-3

Koyuncu, M., Tok, S., Canpolat, A. M., \& Catikkas, F. (2010). Body Image Satisfaction and dissatisfaction, Social Physique Anxiety, Self-esteem , And Body Fat Ratio In Female Exercisers And Nonexercisers, 38(4), 561-570. http://doi.org/10.2224/sbp.2010.38.4.5 61 penghasilan $>3$ juta. Kondisi sosial ekonomi akan mempengaruhi persepsi seseorang terhadap body image. Selain itu menurut Talen and Mann, (2009) menjelaskan bahwa kondisi sosial ekonomi mempengaruhi kebiasaan yang berkaitan dengan pilihan makanan, berhias, aktivitas, kontrol orang tua terhadap anak yang akan mempengaruhi persepsi dan perilaku yang berkaitan dengan penilaian body image.

\section{KESIMPULAN}

Jumlah responden yang memiliki body image yang sangat baik berjumlah 5 orang $(3,35 \%)$, yang memiliki body image baik ada 74 orang $(49,66 \%)$, yang memiliki body image cukup ada 68 orang $(45,64 \%)$ dan yang memiliki body image kurang ada 2 orang $(1,35 \%)$.

Latif, A. A., Um, M., Muhamad, J., Fam, M., Usm, M., Rahman, R. A., ... Usm, M. (2018). Body image dissatisfaction and its determinants among young primaryschool adolescents. Journal of Taibah University Medical Sciences, 13(1), 34-41.

http://doi.org/10.1016/j.jtumed.2017.07 .003

Lipowski, M., Olszewski, H., \& Dykalska-bieck, D. (2016). Gender differences in bodyesteem among seniors: Beauty and health considerations, 67, 160-170. http://doi.org/10.1016/j.archger.2016.0 8.006

Murray, K. M., Byrne, D. G., \& Rieger, E. (2011). Investigating adolescent stress and body image. Journal of Adolescence, 34(2), 269-278. http://doi.org/10.1016/j.adolescence.20 10.05 .004

Murray, K., Rieger, E., \& Byrne, D. (2013). A longitudinal investigation of the mediating role of self-esteem and body importance in the relationship between stress and body dissatisfaction in adolescent females and males. Body Image, 10(4), 544-551. http://doi.org/10.1016/j.bodyim.2013.07 .011

Paans, N. P. G., Bot, M., Brouwer, I. A., Visser, M., \& Penninx, B. W. J. H. (2018). Contributions of depression and body mass index to body image. Journal of Psychiatric Research, 103(April), 1825.

http://doi.org/10.1016/j.jpsychires.2018 .05 .003 
Rawana, J. S., \& Morgan, A. S. (2014). Trajectories of Depressive Symptoms from Adolescence to Young Adulthood: The Role of Self-esteem and Body-Related Predictors, 597611. http://doi.org/10.1007/s10964013-9995-4

Senín-calderón, C., Rodríguez-testal, J. F., \& Perona-garcelán, S. (2017). Body image and adolescence: A behavioral impairment model. Psychiatry Research, 248(December 2016), 121126.

http://doi.org/10.1016/j.psychres.2016. 12.003

Tatangelo, G. L., Mccabe, M. P., \& Ricciardelli, L. A. (2015). Body Image. International Encyclopedia of Social \& Behavioral Sciences (Second Edition, Vol. 2). Elsevier. http://doi.org/10.1016/B9780-08-097086-8.14062-0
Talen, M. R., \& Mann, M. M. (2009). Ob esit y a nd Mental Health, 36, 287-305. http://doi.org/10.1016/j.pop.2009.01.01 2

Vossbeck-elsebusch, A. N., Waldorf, M., Legenbauer, T., Bauer, A., Cordes, M., \& Vocks, S. (2014). German version of the Multidimensional Body-Self Relations Questionnaire - Appearance Scales ( MBSRQ-AS ): Confirmatory factor analysis and validation. Body Image, 11(3), 191-200. http://doi.org/10.1016/j.bodyim.2014.02 .002

Yang, H., Yang, Y., Xu, L., Wu, Q., Xu, J., Weng, E., ... Cai, S. (2017). The relation of physical appearance perfectionism with body dissatisfaction among school students $9-18$ years of age. Personality and Individual Differences, 116, 399-404. http://doi.org/10.1016/j.paid.2017.05.0 05 